\title{
Compression characteristics of spheroidal graphite cast iron pipe members
}

\author{
T. Yamaguchi ${ }^{1} \&$ Y. Kimura $^{2}$ \\ ${ }^{1}$ HINODE Ltd, Japan \\ ${ }^{2}$ New Industry Creation Hatchery Center, Tohoku University, Japan
}

\begin{abstract}
Spheroidal graphite cast iron can be made with shape freedom, and can be used often in critical parts of automobiles and industrial machinery that are designed using the allowable stress design method. However, spheroidal graphite cast iron has been regarded as having low ductility deriving from fracture. It has therefore never been used for structural members for construction purposes. Previous studies have not clarified the plastic deformation capacity and ultimate strength of the spheroidal graphite cast iron members, even though the material properties were estimated using many experimentally obtained results.

As described in this paper, compression tests were performed to investigate the plastic behavior of the spherical graphite cast iron members, and to assess the relation between the collapse mechanism and the width-to-thickness ratio. Tensile strength of samples corresponded to $700 \mathrm{~N} / \mathrm{mm}^{2}, 450 \mathrm{~N} / \mathrm{mm}^{2}$, and $400 \mathrm{~N} / \mathrm{mm}^{2}$. In addition, steel pipe material corresponding to $490 \mathrm{~N} / \mathrm{mm}^{2}$ was selected. Consequently, six specimens were used for the compression test. One was a steel pipe. The specimen diameters were $165.2 \mathrm{~mm}$; the lengths were $450 \mathrm{~mm}$, corresponding to approximately three times the diameter. The specimen thickness was $4 \mathrm{~mm}$ or $6 \mathrm{~mm}$, with a width-to-thickness ratio of 41.3 or 27.5 .

The ultimate strength of spheroidal graphite cast iron pipe members is about twice the yield strength, even though the ultimate strength of the steel piles is equal to the yield strength. A crack was found on the pipe surface at the ultimate strength because the axial stress on the surface changes compression to tension by growing plate bending deformation of local buckling. Spheroidal graphite cast iron pipe members under compression loading exhibit brittle behavior after post local buckling.

Keywords: spheroidal graphite cast iron, pipe members, surface condition, local buckling.
\end{abstract}




\section{Introduction}

Members in steel structures are slender, and the section consists of thin plate. It is important to consider the buckling of members when the steel structures are designed because of the high width-to-thickness and the slender ratio. Furthermore, the steel structure form becomes complicated on a large scale. Therefore, much analysis and experimentation are conducted, with cases inspected based on buckling theory.

In recent years, with rising costs of steel materials, cheap cast iron is often used. Generally, the spherical graphite cast iron material surface is shaped in manufacturing processes. The member is often used with a cast surface. The ductility of the spheroidal graphite cast iron member decreases under tension because of the influence of a cast surface [1]. On the other hand, the compressive characteristics of spheroidal graphite cast iron differ from those of steel because of the presence of graphite within the matrix structure. Previous studies have shown that the graphite is deformed to an elliptical shape by tensile force [2]. It produces a cavity while a matrix structure extends by tension and undergoes plastic deformation. However, the graphite resists compression remarkably. It is difficult to deform [3]. Therefore, the compressive strength of the spheroidal graphite cast iron is said to be about 3 times than the tensile strength. The pearlite matrix compressive stress is about $1800-2000 \mathrm{~N} / \mathrm{mm}^{2}$, and the compressive strength of the ferrite matrix is about $1400-1700 \mathrm{~N} / \mathrm{mm}^{2}[4,5]$. The compressive strength of spheroidal graphite cast iron shows a value higher than the tensile strength. Furthermore, the compressive yield stress is 1.2 times the tensile yield stress [1]. These findings are those of compression examination evaluations done at the specimen level. Moreover, few reports describe the ultimate load and the plastic deformation performance of a member under compression. In numerical analysis, the ultimate behavior of the spherical graphite cast iron member cannot be evaluated exactly because it is not possible to model the graphite matrix structure correctly with irregularities or a component surface.

As described herein, we consider the plastic deformation performance and ultimate strength from results of a compression experiment of spheroidal graphite cast iron pipe member. Also, we consider the mechanism of the tube member collapse.

\section{Experimental procedures}

Generally, the mechanical properties of the spheroidal graphite cast iron are evaluated using the block defined in the Japanese Industrial Standard (JIS) G5502. Fig. 1 presents a block shape and a pulling specimen collection position of a spheroidal graphite cast iron. Tensile specimens were fabricated in a tension test piece by machining the spheroidal graphite cast iron block. However, pulling specimens of carbon steel tubes are tensile specimens with an arc shape taken directly from the steel pipe. The tensile strengths of the spherical graphite cast iron materials correspond to $450 \mathrm{~N} / \mathrm{mm}^{2}, 700 \mathrm{~N} / \mathrm{mm}^{2}$, and $400 \mathrm{~N} / \mathrm{mm}^{2}$. Material 
of $400 \mathrm{~N} / \mathrm{mm}^{2}$ is the material which was heat-treated to $450 \mathrm{~N} / \mathrm{mm}^{2}$. The steel pipe material corresponding to $490 \mathrm{~N} / \mathrm{mm}^{2}$ was selected. After having maintained it at $720^{\circ} \mathrm{C}$ for $5 \mathrm{hr}$ to create a base part of FCD450 ferrite, the furnace was cooled to $400^{\circ} \mathrm{C}$ for $12 \mathrm{hr}$. Heat-treatment later air-cooled it. The chemical compositions of spheroidal graphite cast iron and steel are shown in Table 1. Static tensile tests were conducted at a strain rate of $0.005 / \mathrm{min}$ on $\varphi 10 \mathrm{~mm}$ test pieces machined according to JIS Z 2201 . The $0.2 \%$ proof strength was determined with a strain gauge type expansion indicator. The pipe member and test equipment are presented in Fig. 2. Here, the molten metal of the spheroidal graphite cast iron pipe member is the same as the casting molten metal of the spheroidal graphite cast iron block.

As presented in Fig. 2(a), the axial displacement of the compression test was measured using a displacement meter. Furthermore, as presented in Fig. 2(b), the strain-gauge bonded eight points of a uniaxial gauge to the tube central section at 45 deg intervals to confirm the load uniformity. The specimen diameter was $165.2 \mathrm{~mm}$. Its length was $450 \mathrm{~mm}$, corresponding to approximately three times the diameter. Both specimen ends were smoothed by machining.

Table 2 shows the specimens. Six specimens, of which one is a steel pipe, were used for the compression test. The experiment parameters are material properties, the radius thickness ratio, and the use or non-use of heat-treatment. For cleaning of the surface skin of the casting after casting, the specimen is implementing the shot blast. In addition, shot blasting conditions were adapted to a speed of $73 \mathrm{~m} / \mathrm{s}$ with a $1 \mathrm{~mm}$ steel ball diameter. Here, C4F45-2 performs manufacturing only of the outer surface of the pipe. The inside of the pipe is the casting surface.

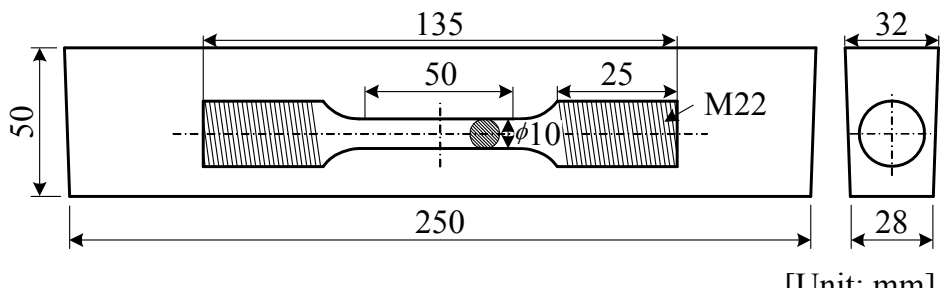

Figure 1: Tensile specimen of spheroidal graphite cast iron.

Table 1: Chemical composition of specimens.

\begin{tabular}{|c|c|c|c|c|c|}
\hline Material & $\mathrm{C}$ & $\mathrm{Mn}$ & $\mathrm{Si}$ & $\mathrm{P}$ & $\mathrm{S}$ \\
\hline FCD700 & 3.621 & 0.420 & 2.070 & 0.012 & 0.013 \\
\hline FCD450 & 3.596 & 0.466 & 1.986 & 0.011 & 0.010 \\
\hline FCD400A & 3.678 & 0.407 & 2.100 & 0.013 & 0.008 \\
\hline STK490 & 0.150 & 0.680 & 0.020 & 0.012 & 0.008 \\
\hline
\end{tabular}




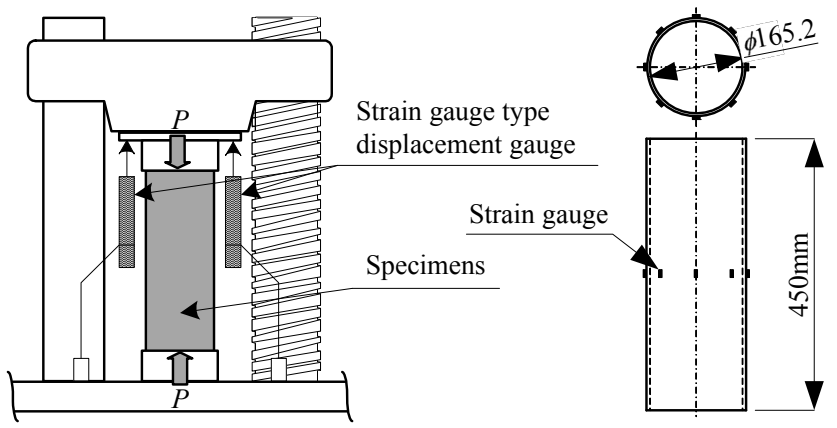

(a) Test set up

(b) Compressive specimen

Figure 2: Test set up and compressive specimen.

Table 2: Compressive specimen list.

\begin{tabular}{|c|c|c|c|c|c|}
\hline $\begin{array}{l}\text { Name of the } \\
\text { experiment }\end{array}$ & Material & $\begin{array}{c}l \\
\mathrm{~mm}\end{array}$ & $\begin{array}{c}D \\
\mathrm{~mm}\end{array}$ & $\begin{array}{c}t \\
\mathrm{~mm}\end{array}$ & $D / t$ \\
\hline C4F70-1 & FCD700 & \multirow{6}{*}{450} & \multirow{3}{*}{165.2} & 4 & 41.3 \\
\hline C6F45-1 & \multirow{3}{*}{ FCD450 } & & & 6 & 27.5 \\
\hline C4F45-1 & & & & \multirow{2}{*}{4} & 41.3 \\
\hline C4F45-2 & & & 161.2 & & 40.3 \\
\hline C6F40A-1 & FCD400A & & \multirow{2}{*}{165.2} & \multirow{2}{*}{6} & \multirow{2}{*}{27.5} \\
\hline C6S49-3 & STK490 & & & & \\
\hline
\end{tabular}

C6F70-1

TSurface condition; 1:Casting surface, 2:Machining surface, 3:Oxide film Material; F70:FCD700, F45:FCD450, F40A:FCD400A, S49:STK490

Pipe thickness; 4:4mm, 6:6mm

Experimental selection; C: Compression experiment

\section{Results and discussion}

\subsection{Tensile test results of materials}

The strain-stress curve is shown in Fig. 3. The representative values of the mechanical properties are shown in Table 3. The stress-strain curve fracture is depicted in Fig. 3(a). Also, the stress-strain curve near $0.2 \%$ yield strength is depicted in Fig. 3(b). Because the steel member is an electric-resistance-welded steel pipe manufactured by plastic working, there is no clear yield point in the curve. Furthermore, the steel's yield stress is calculated using $0.2 \%$ offset method such as the spheroidal graphite cast iron yield stresses. The rise of postyield stress of the spheroidal graphite cast iron is higher than STK490. The FCD700 exhibited breaking elongation of approximately 10\%. However, the breaking elongation of FCD450 was approximately $20 \%$, which was less than that of STK490. Stress of the FCD400A rises slowly; the breaking elongation is equivalent to that of STK490. 


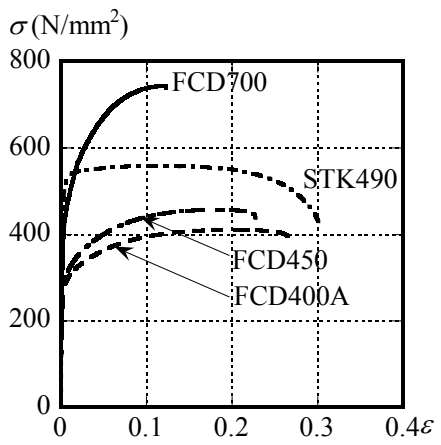

(a) Stress-strain curves

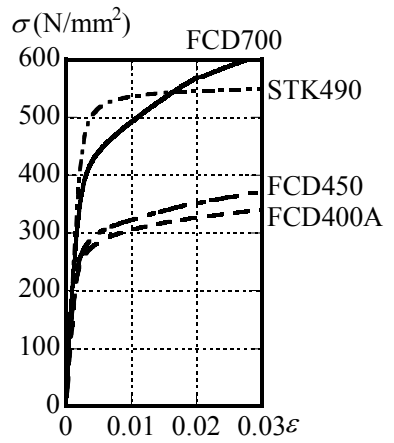

(b) Enlarged view around yield stress

Figure 3: Stress-strain curves.

Table 3: Material property.

\begin{tabular}{|c|c|c|c|c|c|c|}
\hline Material & $\begin{array}{c}\sigma_{y} \\
\mathrm{~N} / \mathrm{mm}^{2}\end{array}$ & $\begin{array}{c}\sigma_{u} \\
\mathrm{~N} / \mathrm{mm}^{2}\end{array}$ & $\begin{array}{c}Y R \\
\%\end{array}$ & $\begin{array}{c}\text { Elong. } \\
\%\end{array}$ & $\begin{array}{c}E \\
\mathrm{~N} / \mathrm{mm}^{2}\end{array}$ & $\begin{array}{c}\phi \\
\%\end{array}$ \\
\hline FCD700 & 428 & 743 & 57.6 & 12.2 & 168,700 & 8.8 \\
\hline FCD450 & 286 & 457 & 62.6 & 21.4 & 166,800 & 20.2 \\
\hline FCD400A & 274 & 411 & 66.7 & 28.0 & 154,100 & 27.9 \\
\hline STK490 & 493 & 568 & 86.8 & 31.0 & 192,300 & 70.8 \\
\hline
\end{tabular}

\subsection{Compression test result}

The load - displacement curve for the compression test is shown in Fig. 4. The vertical axis shows the compressive load obtained by dividing the yield load of the tube. The horizontal axis shows the axial displacement divided by the yield displacement at the yield load. Symbol, $\nabla$ in the figure denotes the maximum load. Fig. 4(a) shows a diagram for wall thickness of $6 \mathrm{~mm}$, with different materials under heat treatment. Fig. 4(b) presents a diagram for wall thickness of $6 \mathrm{~mm}$, with radius thickness ratios of different materials. The compression load acted in a section uniformly.

Stiffness decreases gradually from about $60 \%$ of the yield load. Actually, C6S49-2 portrayed in Fig. 4(a) reached the maximum load by plastic deformation magnification $8 \delta / \delta$. The C6S49-2 is thought to be affected by the residual stress of the cold-work. However, C6F45-1 maintains elasticity near the yield strength. The stress increase is high after the yield, and the maximum load reached 1.9 times the yield load. The C6F40A-1 is the elastic until the yield load. However, the stress increase gradient is lower than when heat treatment is not conducted. The maximum load of C6F40A-1 is lower than the maximum load of $\mathrm{C} 6 \mathrm{~F} 45-1$ at around 1.5 times the yield load. However, the displacement of the maximum load of C6F40A-1 reached $22 \delta_{y}$.

As portrayed in Fig. 4(b), C4F70-1 is lower than the yield load of C4F45-1, but the strain-hardening slope of the yield thereafter is approximately equal. The 
plastic deformation performance of $\mathrm{C} 4 \mathrm{~F} 70-1$ is $8 \delta_{y}$, and the maximum strength is $1.7 P_{y}$. However, the maximum strength and plastic deformation performance of C4F70-1 are lower than those of C4F45-1. The strain hardening slope of the yield after C4F45-1 shows higher results compared to those of C6F45-1. The plastic deformation magnification of C6F45-1 is superior to that of C4F45-1. This result illustrates the effect of work hardening occurring in the shot brass and the uneven state of the surface to the wall thickness [6].

The uneven tube surface reduces the plastic deformation magnification relative to the plate thickness. The C4F45-2 stiffness decreases from C4F45-1. The degree of stiffness after the yield stress is low. It is thought that stiffness degradation of C4F45-2 is the cutting of the work-hardened layer because of machining.

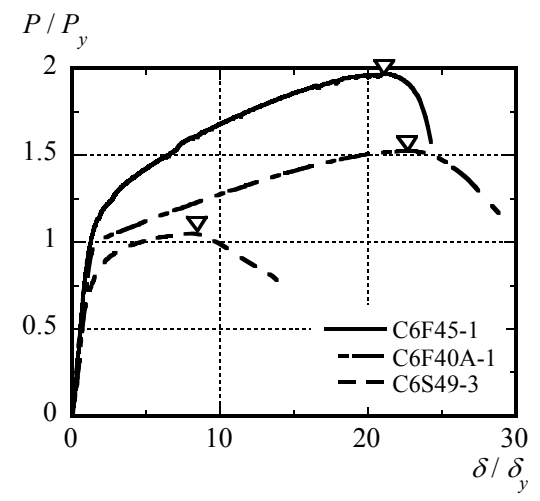

(a) Difference of material property

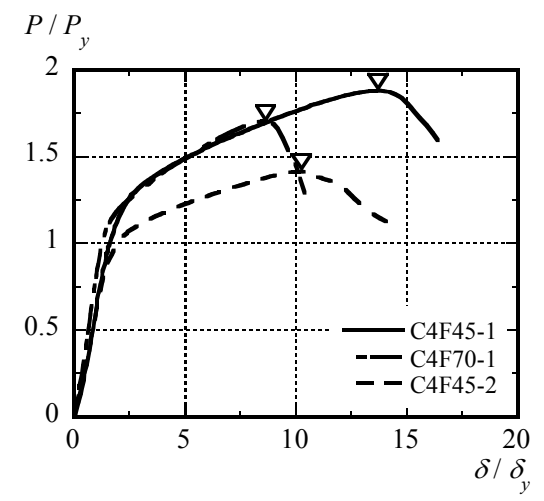

(b) Difference of surface and material property

Figure 4: Compressive load-axial displacement curve. 


\subsection{Collapse mechanism of the spherical graphite cast iron pipe member}

The position of the strain gauge of C6F45-1 is shown in Fig. 5(a). Also, the load-strain curve of C645-1 is shown in Fig. 5(b). The horizontal axis shows the distortion value of axial strain gauge adhered to II of Fig. 5(a). The change of the distorted value increased after the surrender load and produced partial buckling at the maximum load. The end state of C6F45-1 produced a crack with increased tensile stress at the pipe surface. The cause of the crack is the influence of the casting surface.

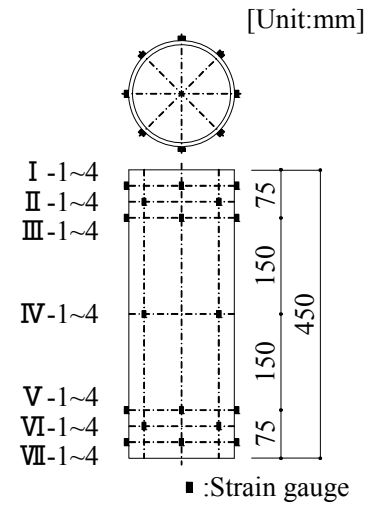

(a) Location of strain gauge

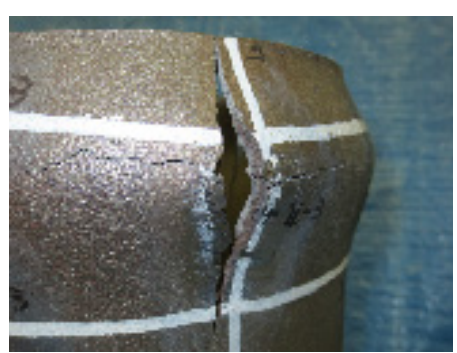

(c-1) Front

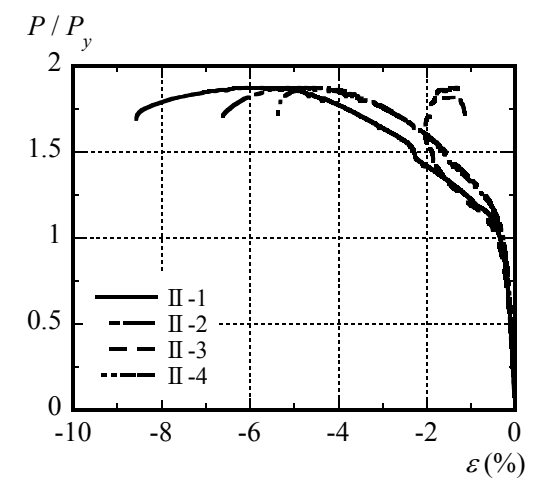

(b) Compressive load-strain curve

(c) Fracture after local buckling

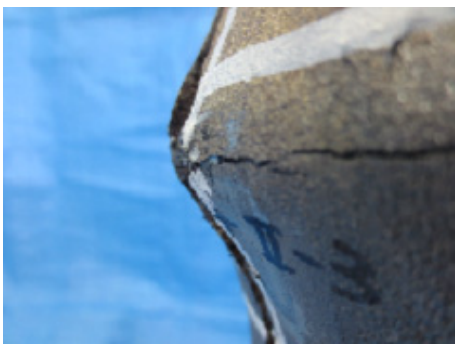

(c-2) Side

Figure 5: Collapse mechanism (C6F45-1).

Compression test results are presented in Table 4. The symbols shown in the table have the following meanings. Yield load, $P_{y}$ is a load calculated by multiplying the yield stress in the cross-sectional area of the tubular member. $P_{u e}$ stands for the maximum load of the load-displacement curve obtained using the compression experiment. $\tau$ represents the ratio of the maximum load to the yielding load. $\mu$ denotes the magnification plastic deformation. It is a value 
obtained by subtracting 1 from the displacement $\delta_{\max } / \delta_{y}$ at maximum load. Cumulative plastic deformation magnification $\eta$ is an integral value up to maximum load $P / P_{y}-\delta / \delta_{y}$. Slope $\kappa$ of the tube member after the yield is a secant gradient of up to a maximum load from the yield load of the load-displacement curve. Maximum strength and plastic deformation capacity of the spheroidal graphite cast iron pipe member are higher than those of steel member. It is believed that compression performance of spheroidal graphite cast iron and have is better than the steel.

Table 4: List of test results.

\begin{tabular}{|c|c|c|c|c|c|c|}
\hline Data item & C4F70-1 & C6F45-1 & C4F45-1 & C4F45-2 & C6F40A-1 & C6S49-3 \\
\hline$P_{y}\left(=A \sigma_{y}\right)[\mathrm{kN}]$ & 857 & 849 & 595 & 576 & 812 & 1509 \\
\hline$\tau\left(=P_{u e} / P_{y}\right)$ & 1.7 & 2.0 & 1.9 & 1.4 & 1.5 & 1.0 \\
\hline$\mu\left(=\delta_{\max } / \delta_{y}-1\right)$ & 7.7 & 20.3 & 12.8 & 9.3 & 21.5 & 7.1 \\
\hline$\eta$ & 11.7 & 31.6 & 19.8 & 12.4 & 28.4 & 8.3 \\
\hline$\kappa$ & 0.11 & 0.05 & 0.07 & 0.05 & 0.03 & 0.01 \\
\hline
\end{tabular}

The final state of the specimen is shown in Figure 6. For C6S49-2 and C6F40A-1, bulge buckling occurs at the top of specimens. For the other specimens, asymmetric local buckling occurs in the middle of the specimens because of the solidification time of the molten metal during specimen production [7]. That is true probably because the material has not been homogenized at the circumferential direction of the tube.

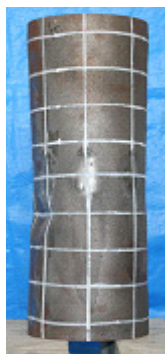

(a) C4F70-1

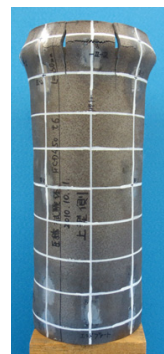

(b) $\mathrm{C} 6 \mathrm{~F} 45-1$

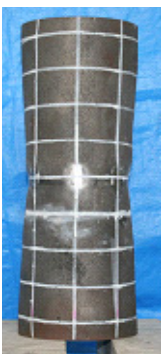

(c) $\mathrm{C} 4 \mathrm{~F} 45-1$

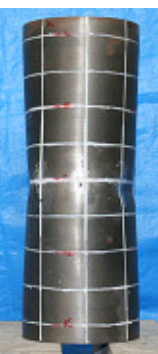

(d) $\mathrm{C} 4 \mathrm{~F} 45-2$

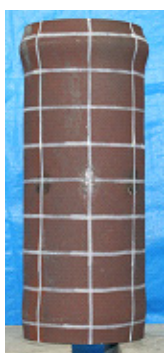

(e) C6F40A-1

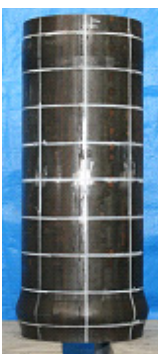

(f) $\mathrm{C} 6 \mathrm{~S} 49-3$

Figure 6: Local buckling behavior of specimens.

\section{Conclusion}

1) Maximum yield strength of the steel pipe is approximately equal to the yield strength. However, the maximum strength of spheroidal graphite cast iron pipe member shows high performance of 1.5 times to 2 times that of a steel pipe. 
2) Spheroidal graphite cast iron pipe member with a cast surface can become brittle in post-buckling behavior under load compression.

3) Buckling mode of spheroidal graphite cast iron pipe members subjected to a compressive load is classifiable into asymmetric type and bulge type. Asymmetric buckling mode results from the heterogeneity of the material affected by the cooling rate during production.

\section{References}

[1] Sokeizai Center, Engineering Data Book VII, 1989, pp. 85-118

[2] T. Yokoyama, Impact Tension and Compression Testing of Ductile Cast Iron with Split Hopkinson Bar, J. Soc. Mat. Sci., Japan, Vol. 45, No. 7, July 1996, pp. 785-791

[3] M. Yano, Effects of Elasticity and Compactness of Graphites on Fatigue Strength of Malleable Iron, Trans. Jpn. Soc. Mech. Eng., Series A, Vol. 51, No. 461, 1985, pp. 132-135

[4] H. Sumimoto, K. Nakamura, On the Characteristic of Impact Fracture Surface of Spheroidal Graphite Cast Iron, Journal of JFS, Vol. 47, No. 5, May 1975, pp. 326-331

[5] H. Sumimoto, K. Nakamura, The Relation between Graphite Deformation and the Displacement of Neutral Axis in the Bending Impact Test of Spheroidal Graphite Cast Iron, Journal of JFS, Vol. 51, No. 12, Dec. 1979, pp. 715-720

[6] J. Yamabe, M, Kobayashi, Effects of Surface Roughness and Residual Stress on Fatigue Strength of Shot Blasted Ductile Cast Irons with Casting Surfaces, Journal of JSMS, Vol. 55, No. 3, Mar. 2006, pp. 301-308

[7] Voigt, R C, Loper, C R Jr, Matrix Structure Development in Ductile Cast Irons, Transactions of the American Foundrymen's Society, Vol. 97, 1989, pp. 595-600 